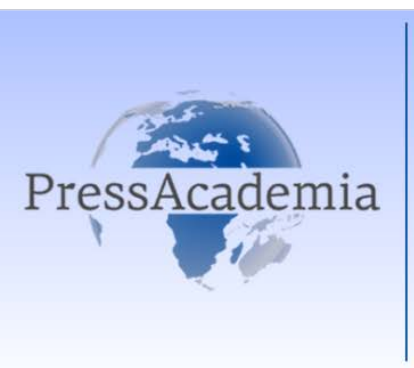

Press Academia Procedía

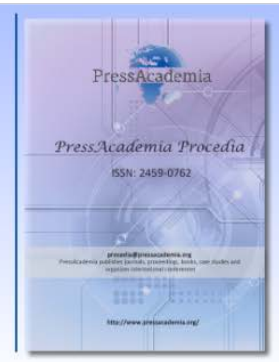

Global Business Research Congress (GBRC), May 26-27, 2016, Istanbul, Turkey.

\title{
A STUDY ON MERSIN IN ORGANIZATIONAL CULTURE REFLECTIONS CULTURE ELECTRONIC NETWORK
}

\section{DOI: 10.17261/Pressacademia.2016118645}

Murat Koc ${ }^{1}$, Linda Ozturk ${ }^{2}$

${ }^{1}$ Çağ Üniversitesi, muratkoc@cag.edu.tr

${ }^{2}$ Çă̆ Üniversitesi, lindaozturk1@hotmail.com

\begin{abstract}
Organizational culture; productivity an densurethe effectivenessandadded value in terms of creativityor creation, the organization; motivate towards the corporate objectives, the creation of organizational commitmentand sense of belonging, system is the in tegrityoverlap witht heobjectives of individuals and instituti ons that prepare the basis for development principles. Integrity of this system is supplied from a number of elements of organizational culture; business mission, strategies, andvalues of a number of organizational culture dynamics, structures and processes, norms, ceremonies, such as symbols. There continues to be proactive structure, Dynamics and elements of the members of the organization to learnand follow the organizational culture based on there quirementsandoutside the building process remainin different tor enewingand change. As innovation and change brought about this particular technological progress are activelyused electronic network of individual sand there forethe organization of cultural evolution, emerges in the context of organizational culture to be considered as a matter of business today, they providethedegree of compliance. Examination is the subject of this work, create a web site ownedby the organization they created, businessesvia an electronic network in this context.Discussed the mission and vision of relations in this work; Mersin Chamber of Commerce\&Industry registered corporation with in the first 5,000 companies who pay most of the taxes, that mosttaxlast two years have been assessedby the top 100 companies in this work. The obtainedresults of research; the majority of the 100 companies have web sites. However, these companies, is variable to give locationin formation mission and vision.
\end{abstract}

Keywords: Mission, vision, electronic network culture.

JEL Codes: L10, L20, L21, M10, M14.

\section{ÖRGÜTSEL KÜLTÜRÜN ELEKTRONIK AĞ KÜLTÜRÜNE YANSIMALARI ÜZERINE MERSIN ILINDE BIR ARAŞTIRMA}

\section{ÖZET}

Örgüt kültürü; verimliliğin, etkinliğin ve yaratıcılığın sağlanması veya katma değer yaratılması bakımından, örgütün; kurum hedeflerine doğru motive edilmesi, örgütsel bağlılık ve aidiyet duygusunun oluşturulması, geliştirilmesi ve kurum ile birey amaçlarının örtüşmesi esasına dayanak hazırlayan bir sistem bütünlüğüdür. Bu sistem bütünlüğü; işletme misyonu, stratejileri, yapıları ve süreçlerini içeren bir takım örgüt kültürü dinamiklerinden ve değerler, normlar, seremoniler, semboller gibi bir takım örgüt kültürü unsurlarından beslenmektedir. Bu dinamiklerin ve unsurların örgüt üyelerince öğrenilmesi ve takip edilmesi gerekliliğine dayanan örgüt kültürü, inşa süreci dışında da kendini yenileyen ve değişimlere kayıtsız kalmayan proaktif yapılanmayı sürdürmektedir. Bu konuda özellikle, teknolojik ilerlemenin getirdiği yenilik ve değişim itibariyle, aktif olarak kullanılan elektronik ağların bireylerin ve dolayısıyla örgütlerin kültürel evrimine, örgütsel kültür bağlamında işletmelerin ne derecede uyum sağlayıp sağlamadıkları günümüzde önemle durulması gereken bir husus olarak karşımıza çıkmaktadır. Bu bağlamda; işletmelerin elektronik ağ aracılı̆̆ıyla, kuruma ait internet sitesi oluşturup oluşturmadıkları; misyon, vizyon bağlamında yer verip vermemeleri bu çalışmanın inceleme konusunu oluşturmaktadır. Misyon ve vizyon iliş̧isinin ele alındığı bu çalışmada; Mersin Ticaret ve Sanayi Odası' na kayıtlı, kurumlar vergisini en çok ödeyen ilk 5.000 şirket içerisinden, son iki yılda en çok vergi veren ilk 100 şirket araştırma kapsamına alınarak incelenmiştir. Elde edilen araştırma sonuçlarında; 100 şirketin büyük çoğunluğu internet sitesine sahiptir. Ancak bu şirketlerin, misyon ve vizyon bilgileri değişkenlik göstermektedir.

Anahtar Kelimeler: Misyon, vizyon, elektronik ağ kültürü.

JEL Kodları: L10, L20, L21, M10, M14. 


\section{GiRiş}

Elektronik ağlar, mevcut altyapısı ve yaygınlığı itibariyle bireysel iletişimin ve bilhassa işletmelerin yönetim fonksiyonlarını destekleyen ayrılmaz bir parça haline gelmiştir. Elektronik ağların bu bağlamda ana unsur olma özelliği, sosyal ve bireysel yaşam dışında iş çevresinin de merkezine oturmuş durumdadır. Özellikle elektronik ağ kültürünün varlığı ve önemi her kademede yer alan iş gören açısından yadsınamayacak düzeyde belirginleşmiştir. Her an her şekilde kullanılabilirliği nedeniyle elektronik ağlar etkileşim ajanı olarak bir görev üstlenmiş durumdadır. Bu noktada işletmelerin de bu elektronik ağ ajanını ne kadar dikkate aldıkları ve nasıl kullandıkları örgütsel kültürün algılanması ile doğru orantılı olabilmektedir. Bu nedenle özellikle işletmeler için stratejik önem arz eden misyon ve vizyon bildirgelerinin elektronik ağa yansıma biçimleri, dereceleri ve kalitesi açısından irdelenmesi gereği doğmuştur. Nitekim bir organizasyonun başarısında yatan en önemli faktörlerin belirleyicileri arasında iyi belirlenmiş; şirkete, pazara ve sektöre en iyi şekilde deklare edilmiş vizyon ve misyon ifadeleri yer almaktadır (Aktan, 2008:19). Bu önem doğrultusunda çalışmada, elektronik ağ kültürünün örgüt kültürüne yansımaları yalnızca misyon ve vizyon ifadelerine yer verilmesi açısından ele alınmıştır.

\section{MisYON VE VIZYON}

Misyon, örgütün varoluş sebebidir (Kılıç, 2010:91). Örgütün kendine özgü ve sürekliliği olan bir hedefini gerçekleştirmeye yönelik çabalarını teşvik eden yazılı ve resmi bir dokümandır. Bir örgüte ne iş yaptığını açıkça ifade etme, genel amaç ve ayırıcı yeteneğini vurgulama olanağı sağlayan cümle ya da cümleler topluluğudur. En basit tanımıyla misyon, örgütün varlık nedeninin ifadesidir ve stratejik yönetimin kilit bir parçasıdır (Doğan, 2008:94). Misyon ile ilgili, çeşitli kavramlar ve tanımlamalar mevcuttur. Ancak Bart, (2007:683) yaptığı çalışmada, misyonun ortak ifadelerinin inanç, vizyon, amaç ve değerler olduğunu belirtmiştir. İçeriklerinde ise; işletme felsefesi veya ilkelerinin yer aldığını vurgulamıştır.

Misyon, örgütün, şu anda neden var olduğunu, hedefine ulaşmak için izleyeceği rotayı tanımlamaktadır. Misyon, örgüt fonksiyonları için bir rehber gibi çalışmaktadır. Örgütün amacı ya da stratejik hedefi değildir, misyon çok daha büyük bir amaca hizmet etmektedir. Önemli olan çok iyi ifade edilmiş süslü değer ve misyon ifadeleri oluşturmak değildir, bu kavramlarla ilgili sağlam bir anlayışa sahip olmaktır (Kılıç, 2010:91). Strateji kuramları literatüründe işletmeler arası başarı farklarının nedenleri araştırılırken, başarılı olmak için işletmelerin niçin var olduklarını açıklamak amacıyla oluşturacakları misyon ifadelerini, tüm etkileşenlerine bildirmesi gerektiği vurgulanmaktadır (Köseoğlu, 2008:90).

Her örgütün yazılı olsun ya da olmasın bir misyona sahip olduğu söylenmektedir. Misyon, herhangi bir örgütün en önemli varoluş sebebidir ve stratejik amaçlarını nasıl gerçekleştireceğini belirleyen çerçeveyi oluşturmaktadır. Genel ve stratejik amaçları aynı olan örgütleri birbirinden ayırt etmeye yarayan ve örgütün kimliğini belirleyen temel özellik misyonla kazanılmaktadır (Kılıç, 2010:93). Misyonun, en önemli yönetim araçlarından biri olarak kabul edilmesinin nedenlerinden biri misyon ifadelerinin iç ve dış piyasalar üzerinde güçlü bir motivasyon etkisi oluşturduğuna ve bir misyon ifadesine sahip olmakla bundan pek çok faydalar elde edilebileceğine olan inançtır (Köseoğlu, 2008:91). Misyon ifadelerinde karşılaşılan problem ise, örgüt misyonunun yeterince ayırt edici nitelikte ortaya konulamamasıdır. Aynı sektörde faaliyet gösteren benzer örgütlerin -hastane ya da üniversite gibi- misyon ve vizyon ifadelerinin incelenmesi ile birini diğerinden ayırt etmek mümkün değilse, bu kavramların işlevini yerine getirmediğini söylemek mümkündür (Kılıç, 2010:92-93). Nitekim, Köseoğlu' nun (2008) KOBi' leri ele aldığı çalışmada; KOBI' lerin misyon ifadelerinde kullandığı öğelerin benzer olduğu ortaya çıkmıştır.

İyi yaratılmış bir misyon örgütsel performansı pozitif yönde etkilemektedir. Özellikle misyon ve örgütsel performans ilişkisinin faydalarının; iyileştirilmiş kaynak tahsisi, güçlendirilmiş meşruiyet ve paylaşılan değerlerin pekiştirilmesi olduğu vurgulanmaktadır (Kılıç, 2010:92). Bir çok çalışmada misyon ifadelerinin örgütsel davranışı, performansı ve kurumsal yönetimi etkilediği belirtilmektedir (Köseoğlu, 2008:91).

Vizyon ise; insanların ve örgütlerin odaklandıkları hedefleri gerçekleştirebilmek için yarattıkları düşünsel modellerdir. Düşünsel anlamda yaratılan vizyon arzulanabilir ve gerçekleştirmeye değer olmalıdır. Örgütün gelecekteki başarısı için bir rotadır veya örgütün oluşturduğu amaçlardır. Şevk verici, ahlaklı ve anlamlı olmaya ihtiyaç duyan vizyon, değişik çabaları yönetmek için kullanılan geleceğin istenen halidir (Kılıç, 2010:88). Kısaca 
örgütün gelecekte ne olmak istediğinin bir ifadesidir. Tahminler ve kararlar bütünüdür. Vizyon örgütün gelecekte ulaşmak istediği hedefi ortaya koyan, bu hedefin hangi temeller üzerinde kurulacağı ve nasıl bir geleceğin oluşturulmak istendiğini ortaya koyan, yol gösteren ifadedir. Vizyonun iyi bir yol gösterici olabilmesi için de, geleceğin, insanların kolayca anlayıp kavrayabileceği biçimde tanımlanması ve ona ulaşmanın anlamını ilgililere anlatacak şekilde dile getirilmesi ve basit olması gerekmektedir. Tüm örgüt kademelerinde benimsenmesi, heyecan ve gurur verici olmayı sağlaması gerekmektedir (Kılıç, 2010:89).

Vizyon örgüt için; gerçekçi, inanılır, çekici bir gelecek ve örgütün ne olduğunu ve nereye gitmek istediğini anlamaya ihtiyacı olan herkes için yol gösteren bir tabela oluşturmak için kaynakları ve yetenekleri kullanarak geleceğe yönelik enerji verici bir fikirdir ve örgütün gelecekte layık olacağı ve çalışanlarca paylaşılan bir ileri görüşlülüğe sahip olmasıdır. Bu, bir taraftan yol gösterici, diğer taraftan da çalışanları örgütün geleceği ile ilgilenmelerine odaklayan, bağlayıcı bir planlama ve motivasyon aracıdır. Bu nedenle işletmenin amaç ve hedefleriyle eşgüdüm içinde vizyon oluşturması gerekmektedir (Eren vd., 2003:61).

Organizasyonun her zaman yazılı bir vizyon ve misyon bildirgesinin olması gerekliliği yoktur. Ancak, Yazılı bir bildirgenin bulunması organizasyonun bildirgede belirtilen ilke, değer ve ortak inançlara daha fazla önem vermesi konusunda gizli bir baskı oluşturabilmektedir (Aktan, 2008:20). Strateji, amaç ve hedef belirleme ve vizyon oluşturma çabaları diğer kültürel özelliklere nazaran, yüksek şirket performansının başlıca belirleyicileri olarak görülmektedir. Nitekim vizyon belirlemede öncü şirketlerin kendi endüstrilerinde lider konumunda ve kendi rakiplerince taklit ve takdir edilen, dünya çapında etkili olan kuruşlar olduğu ve şirketlerinin uzun dönem finansal oranlarının iyi olduğu ve sadece iyi ve başarılı değil aynı zamanda sıkıntılara karşı sabırlı oldukları görülmektedir (Eren vd., 2003).

Son yıllarda yönetim alanında yapılan çalışmalarda etkin bir vizyona ve misyona sahip olan organizasyonların, vizyon ve misyonu açık ve belirli olmayan organizasyonlara karşı daha başarılı oldukları konusunda bir görüş birliği olduğu gözlemlenmektedir. Yönetim alanında tanınmış uzmanlar da, başarı için organizasyonda yazılı bir vizyon/misyon bildirgesinin hazırlanması ve bu bildirgenin tüm organizasyon çalışanları tarafından paylaşılan ortak değer ve inançları yansıtması gerektiğini ifade etmektedirler. Ayrıca vizyon/misyon bildirgesinin bir tür "yazılı anayasa" şeklinde düzenlenmesi yönetim dünyasında giderek artan bir şekilde kabul görmektedir (Aktan, 2008:19).

Çalışanlar kendi örgütlerinin amaç, yöneliş ve özelliklerini berrak bir biçimde anlarlarsa örgütlerine daha büyük bir destek ve bağlılık göstereceklerdir (Melewar, 2003:176). Ayrıca, vizyon ve misyon bildirgelerinde yazılı olan değerler ve ilkelerin zaman içerisinde değişebileceğinin kabul edilmesi gerekmektedir. Yeni fikirler ve yeni global değerler çerçevesinde ilkelerin, değerlerin ve inanç sistemlerinin de değişmesi mümkün olabilmektedir (Aktan, 2008:20). Bu hususta değişen çevreye bağlı olarak, elektronik ortamın organizasyonun bütününe etki ettiği gerçeğinden hareketle, elektronik ağ temelli yeni bir kültürün oluştuğunu söylemek mümkündür.

\section{ELEKTRONIK AĞ KÜLTÜRÜ}

International ve network kelimelerinin birleşmesinden oluşan İnternet kavramı, bir teknolojik ürün, bilgi ve iletişim aracı olarak günümüzde mesaj, dosya, program gibi birçok unsurlarıyla bilimden ticarete, müzikten sinemaya ve kültüre hemen her alanda kullanılabilmektedir (Belin ve Yıldız, 2011:10-22). Teknoloji kültürü ya da elektronik ağ kültürü olarak adlandırılabilecek bu yeni kültür, bireylerin teknolojiyi kullanırken oluşturdukları yeni yaşam biçimleridir (Özaydın, 2010:3). Bu noktada elektronik ağ kültürünü; birey, örgüt, toplum, kültür ekseninde birbirini etkileyen ve firma düzeyinde de kendini hissettiren teknolojik tepkime olarak tanımlamak mümkündür (Yılmaz ve Aydın, 2013:2).

Teknoloji kültürü ile iletişim biçimimiz, ulaşımımız, çalışma şekillerimiz, kullandığımız kavramlar ve çevremizde olup bitenleri algılayışımız da önemli dönüşüme uğramıştır. Teknoloji ile birlikte oluşan teknoloji kültürü, günümüzde modern teknolojinin ortaya çıkışı ile değişime uğramış ve toplumda oluşan her kültür gibi gelişmelerin hız kazanması ile birlikte bu yeni kültür de toplumda ve iş dünyasında yerini almıştır (Özaydın, 2010:1-3). Nitekim, Walter J. Ong, elektronik teknolojinin hayatımıza kattığı çeşitli araçlar vasıtasıyla, "ikincil sözlü kültür çağı”na girdiğimizden bahsetmektedir. Teknolojinin, kültürel ürünler üzerinde dönüştürücü bir etki yarattığını ve onlara yeni bir şekil kazandırdığını vurgulamaktadır (Ong' dan aktaran Çamkara, 2007:27-28). Bu dönüştürücü etki iki boyutta ortaya çıkmaktadır. Birincisi, teknoloji devriminin haberleşmede yarattığı 
olağanüstü hızlanma ve haberleşme alanının genişlemesi; ikincisi ise elektroniğin sadece haberleşmede devrim yaratmakla kalmayıp, ekonominin her kesiminde yeni olanaklar ve üretim biçimleri ortaya çıkarmasıdır (Yalçın vd., 2009:56). Bu durum, süreçlerini yenilemeyen işletmelerin yok olma durumuyla karşı karşıya kalacaklarının bir göstergesi olarak ortaya çıkmaktadır. Örgütlerin varlıklarını sürdürmelerinin temel koşulu da, doğal olarak değişimin gereklerine uygun tepkiler geliştirebilmelerine bağlı hale gelmektedir (Yalçın vd., 2009:56).

Elektronik ağ kültürü aynı zamanda gelişen teknolojiden bir organizasyonun yönetim fonksiyonları bağlamında; hangi ölçüde, nasıl istifade ettiğinin de bir göstergesi olarak ön plana çıkmaktadır. Esasında teknolojik yeteneklerin iş ortamına ve örgüte yansıtılması ve bundan pozitif bir değer olarak istifade edilmesi ve örgütsel kültürün geliştirilmesi yönünde bir araç olarak kullanılması başlı başına yeni bir çalışma alanı olarak ortaya çıkmaktadır. Bu noktada işletmelerin misyon ve vizyon bildirgelerinin elektronik ağlara yansıma derecelerinin değerlendirilmesi ve bu iki kavramın elektronik tanıtım sayfalarında yer almasının değişimin gereklerine ayak uydurabilme becerilerinin bir göstergesi olacağı ve elektronik ağ kültürünün örgütsel kültür bağlamında ne kadar içselleştirildiğinin ciddi bir yansıması olacağı değerlendirilmiştir.

\section{ARAŞTIRMANIN METODOLOJISI}

\subsection{Araştırmanın Amacı}

Araştırma, şirketlerin elektronik ağ kültürlerinin örgütsel kültürün bir yansıması olan misyon ve vizyon ifadelerinin WEB sayfalarında ne kadar yer aldığının ve elektronik ağ kültürlerinin şirket tarafından ne kadar içselleştirildiğinin belirlenmesi amacını taşımaktadır. Ayrıca çalışmada bu şirketlerin Web sayfalarında, İnsan Kaynağı ibaresine yer vermeleri, şekilsel ve içeriksel yönden de ele alınarak incelenmiştir.

\subsection{Araştırmanın Evreni ve Örneklemi}

Mersin Ticaret ve Sanayi Odası'na kayıtll, kurumlar vergisini en çok ödeyen ilk 5.000 şirket içerisinden, son iki yılda en çok vergi veren ilk 100 şirket araştırma kapsamına alınarak incelenmiştir. Yıllar itibariyle örnekleme alınan şirketler 2013-2014 yıllarını kapsayan dönem aralığında vergilendirmeye tabi olan şirketlerdir.

\subsection{Araştırmanın Veri Toplama Yöntemi}

Veriler; Mersin Ticaret ve Sanayi Odası'na kayıtlı bulunan, kurumlar vergisini en çok ödeyen ilk 5.000 şirket içerisinden, son iki yılda en çok vergi veren ilk 100 şirketin web sayfalarının internet ortamında tek tek incelenmesi ile elde edilmiştir. Veriler, Mersin Ticaret ve Sanayi Odasının web sitesinde yer alan kamuya açık verilerden yararlanılarak, kurumlar vergisini en yüksek düzeyde ödeyen şirketlerin matrah ve tahakkuk vergi aralığı ve yıllara göre dağıımı tespit edilerek elde edilmiştir.

\section{ARAŞTIRMA BULGULARI}

Araştırma kapsamına dahil edilen işletmelerin ilk etapta sektörel dağııımları ele alınmıştır.

Tablo 1: Sektör Dağııımları

\begin{tabular}{|ll|}
\hline Sektörler & Şirket Sayısı \\
\hline Depolama & 2 \\
\hline Eğitim & 2 \\
\hline Sağlık & 4 \\
\hline Enerji & 5 \\
\hline Hizmet & 6 \\
\hline Tarım & 13 \\
\hline İnşaat & 13 \\
\hline Taşımacılık & 16 \\
\hline İmalat & 19 \\
\hline Ticaret & 20 \\
\hline Toplam & 100 \\
\hline
\end{tabular}


Tablo-1' de görüleceği üzere; 100 işletmenin 2' si depolama, 2' si eğitim, 4' ü sağlık, 5' i enerji, 6' sı hizmet, 13' ü tarım, 13' ü inşaat, 16' sı taşımacılık, 19’ u imalat ve 20' si ticaret sektöründe yer almaktadır.

İkincil olarak, şirketlerin web sitelerinin olup olmadığı, olduğu durumda, misyon ve vizyon ifadelerine yer verip vermedikleri, incelemeye alınmıştır. Elde edilen bulgulara Tablo 2' de şu şekilde yer verilmiştir.

Tablo 2: Şirketlerin Misyon ve Vizyon Bildirgelerini Web Sitelerine Yansıtmaları

\begin{tabular}{|lc|}
\hline & Şirket Sayısı \\
\hline Sadece Misyon ifadesine yer veren & 5 \\
\hline Sadece Vizyon ifadesine yer veren & 2 \\
\hline Hem Misyon hem Vizyon ifadesine yer veren & 43 \\
\hline Web sayfası olduğu halde Misyon ve Vizyon ifadesine yer vermeyen & 33 \\
\hline Web Sayfası bulunmayan & 17 \\
\hline Toplam & 100 \\
\hline
\end{tabular}

Tabloda görüleceği üzere; yalnızca misyon ifadesine yer veren 5 şirket ve yalnızca vizyon ifadesine yer veren 2 şirket bulunmaktadır. Bu 100 şirketin 43 tanesi web sitesinde hem misyon hem de vizyona yer vermiştir. 33 şirket ise; web sitesi olduğu halde misyon ve vizyona yer vermemiştir. Ayrıca kurumlar vergisini en çok ödeyen ilk 100 şirket arasında bulunmalarına rağmen, 17 şirketin web sitesi bulunmamaktadır.

Incelemeye alınan bir diğer özellik ise, şirketlerin web sitelerinde insan kaynağına yer verip vermedikleri üzerinedir. Bu inceleme sırasında; insan kaynağına yer veren şirketler, şekilsel yönden yer verenler ile içeriksel insan kaynağına yer verenler şeklinde ayrıca kategorilendirilmiştir.

Tablo 3: Şirketlerin İnsan Kaynakları ifadesini Web Sitelerine Yansıtmaları

\begin{tabular}{|lc|}
\hline & Şirket Sayısı \\
\hline Sadece İnsan Kaynakları ifadesine yer veren (şekilsel) & 16 \\
\hline İnsan Kaynakları ifadesine yer vermeyen & 45 \\
\hline İnsan Kaynakları ifadesinde çalışan içeriği bulunan & 22 \\
\hline Web Sayfası bulunmayan & 17 \\
\hline Toplam & 100 \\
\hline
\end{tabular}

Şirketlerin İnsan Kaynakları içeriklerini web sitelerine yansıtmaları bakımından da ele alınan çalışma sonuçlarına göre; İnsan Kaynakları başlığına yer veren ancak içerik bakımından yalnızca başvuru formuna yer veren şirket sayısı 16' dır. Web sitesi olduğu halde, İnsan Kaynakları ifadesine hiç yer vermeyen şirket sayısı ise, $45^{\prime}$ tir. İnsan 
Kaynakları, personelimiz, ekibimiz, yönetim kurulu, çalışanlarımız ve organizasyon şeması gibi başıklar altında isimlere yer veren şirket sayısı 22' dir. 17 şirketin ise web sitesi bulunmamaktadır.

Yoğun rekabetin yaşandığı tüm endüstri kollarında yenilikçi olmak, işletmeler için hayatta kalabilmenin en önemli ve zaruri faktörlerinden biri haline gelmiştir (Kılıç vd., 2014:37). Yalnızca ürün ve hizmetlerin yenilik içinde olması elektronik ağ kültürü içinde bulunulan bu dönemde yeterli görünmemektedir. Aynı zamanda kültür bağdaşıklığı içsel ve dışsal etmenlerin varlığının kabulü ve stratejilerle paralel bir perspektif ve yönlendirme çevresinde olmalıdır. Sürdürülebilirlik, büyüme ve gelişme amacı güden işletmelerin internet erişim ve kullanım oranlarını göz ardı etmemeleri gerekmektedir. Aşağıdaki tabloda Türkiye' de yıllara göre bilgisayar ve internet erişim ve kullanım oranlarına yer verilmiştir.

Tablo 4: Türkiye' de Yıllara Göre Bilgisayar Ve İnternet Erişim Ve Kullanım Oranları

\begin{tabular}{|l|l|l|l|l|l|c|c|c|c|c|}
\hline & \multicolumn{4}{|c|}{ Bilgisayar Erişim Ve Kullanım Oranları } & \multicolumn{4}{c|}{ Internet Erişim Ve Kullanım Oranları } \\
\hline & $\mathbf{2 0 1 1}$ & $\mathbf{2 0 1 2}$ & $\mathbf{2 0 1 3}$ & $\mathbf{2 0 1 4}$ & $\mathbf{2 0 1 5}$ & $\mathbf{2 0 1 1}$ & $\mathbf{2 0 1 2}$ & $\mathbf{2 0 1 3}$ & $\mathbf{2 0 1 4}$ & $\mathbf{2 0 1 5}$ \\
\hline $\begin{array}{l}\text { Ücretli, maaşlı, } \\
\text { yevmiyeli çalışanlar }\end{array}$ & 66,8 & 67,1 & 69,0 & 68,5 & 67,6 & 64,6 & 66,0 & 67,5 & 71,2 & 74,9 \\
\hline İşveren & 78,8 & 77,1 & 78,0 & 79,4 & 82,8 & 76,6 & 76,6 & 78,6 & 81,6 & 85,1 \\
\hline
\end{tabular}

Kaynak: Tüik, 2015.

Bu oranlar dikkate alındığında bilgisayar ve internet kullanım ve erişiminde yıllara göre artış olduğu görülmektedir. İşverene göre, düşük gelire sahip olarak değerlendirilen ücretli, maaşlı ve yevmiyeli çalışanların bilgisayara ve internete erişimi de bu noktada giderek artmıştır. Bu artışın işverenin daha yüksek gelir ve daha iyi olanaklara sahip olduğu varsayımına rağmen, Tablo 4' de yer alan veriler incelendiğinde, çalışanın internet erişim ve kullanımının azımsanmayacak düzeyde olduğu görülmektedir. Çalışmada elektronik ağ kültürü olarak değerlendirdiğimiz ve işletmelerin bunu göz önünde bulundurma gerekliliği, tablodaki veriler ışı̆̆ında, yazııı bildirgelerden daha çok elektronik bildirgelerin önem kazanmaya başladığı üzerinedir.

\section{SONUÇ VE ÖNERILER}

Örgütün gelecekteki fotoğrafını bugünden oluşturma anlamına gelen vizyon, örgütün geleceğine ait resmi; misyon ise, bu vizyonu gerçekleştirmek için bir kurumsal araç niteliğindedir. Misyonun örgüt üyelerine bir istikamet ve hedef kazandırmak amacıyla belirlenmesi ve örgütü benzer örgütlerden ayırt etmeye yarayacak uzun dönemli bir görev ve ortak bir değer (Karakışla, 2009:49) olarak karşımıza çıktığı ve örgüt kültürünün bir parçası olduğu konusunda yaratılacak durumsal farkındalık; işletmeler içerisindeki kültürün şekillenmesi ve olumlu anlamda yönlendirilmesi, örgütün hem yönetim biçimini hem de rekabet koşullarını etkileyecektir (Erdem vd., 2010:75). Ayrıca işletme misyonu, stratejileri, yapıları ve süreçleri ile örgüt kültürü arasında tutarlılığın sağlanması elzemdir (Baker, 2002:8; O'Donnell veBoyle 2008:5). Örgüt gerçeğinin görülmesine imkan veren düşünsel bir yapı, bir paradigma olarak görülen örgüt kültürü (Güçlü, 2003:148), aynı zamanda örgütlerin kendi amaç ve faaliyet yapısından kaynaklanan özellikleri ile toplumsal değerlerin bir birleşimi olarak karşımıza çıkmaktadır (Erdem vd., 2001:76). Bu sebeple, örgütlerin faaliyette bulundukları yakın ve uzak çevre unsurlarındaki hızlı değişim örgütlerin kültürünü de etkilemektedir (Kaya, 2008:121). Özellikle günümüz elektronik ağ kültürünün gerek çalışan gerekse tüketici temelli etkisini hissettirmesi işletmelerin farkına varması gereken bir kültür olarak iki boyutta karşımıza çıkmaktadır. Elektronik ağ kültürünün işletme paydaşları tarafından çevrelendiği ve işletmenin iç ve dış çevredeki uyumun sürdürebilirliği bakımından değer taşıdığı gözden kaçırılmaması gerekmektedir. Verimliliğin, etkinliğin ve yaratıclığın sağlanması veya katma değer yaratılması boyutunda örgütün; kurum hedeflerine doğru motive edilmesi, örgütsel bağlılık ve aidiyet duygusunun oluşturulması, geliştirilmesi ve kurum ile birey amaçlarının örtüşmesi esasına dayanak hazırlayan bir sistem bütünlüğü oluşturması (Kaya, 2008:121) sebebiyle de çalışanların, işletmenin amaç ve hedeflerini, gelecekte nerede olacağını yansıtan misyon ve vizyon ifadelerinin paylaşılması zorunlu hale gelmektedir. 
Araştırma bulgularında yer aldığı üzere; yalnızca misyon ifadesine yer veren 5 şirket, yalnızca vizyon ifadesine yer veren 2 şirket bulunmaktadır. Şirketlerin 43 tanesi web sitesinde hem misyon hem de vizyona yer verirken; 33 şirket ise; web sitesi olduğu halde misyon ve vizyona yer vermemiştir. 17 şirketin de web sitesi bulunmamaktadır. Diğer bulgular arasında yer alan; şirketlerin İnsan Kaynakları içeriklerinin web sitelerine yansıtmaları bakımından elde edilen sonuçlar şu şekildedir: Yalnızca İnsan Kaynakları başlığına yer verip, içeriğinde ise yalnızca başvuru formuna yer veren şirket sayısı 16' dır. Web sitesi olduğu halde, Insan Kaynakları ifadesine hiç yer vermeyen şirket sayısı ise, $45^{\prime}$ tir. İnsan Kaynakları, personelimiz, ekibimiz, yönetim kurulu, çalışanlarımız ve organizasyon şeması gibi başlıklar altında isimlere yer veren şirket sayısı ise 22' dir. 17 şirketin ise web sitesi bulunmamaktadır. Şirketlerin il bazında en çok vergi veren şirketler konumunda olmalarına rağmen, misyon ve vizyonun şirket paydaşlarından önemli iki taşını oluşturan müşteri ve çalışan perspektifindeki öneminin dikkate alınmadığı sonucuna ulaşıımaktadır. Çalışanların yer aldığı kurumda şirketin görev ve politikalarının çalışanlar tarafından algılanmasının önemi ve "elektronik ağ kültürü döneminde" olunduğu göz önünde bulundurulmamasının yanında sektörel anlamda firmaların tanınırlığı ve bilinirliğinde elektronik ağ kültürünün bir reklam aracı olarak kullanıldığı değerlendirmesine ulaşılmaktadır. Bunun yanında gelecek hedeflerini yansıtan vizyon ifadesinin ise, çalışanlara yeterince aktarılmamasının, tatmin ve performans düzeyinde çalışanların negatif geri bildirim sağlamasına yol açabileceği konusundaki durumsal farkııı̆ın yeterli düzeyde olmadığı sonucu da bir başka değerlendirme olarak ön plana çıkmaktadır.

Çalışanlar tarafından misyonun ve vizyonun bilinmesi, şirketin ileride yer alacağı pozisyonda çalışanların kendilerini kurumun neresinde görmek istediklerine bağlı olarak tatmin, aidiyet ve performansta pozitif geri bildirim elde edilmesine olanak sağlayabileceği konusundaki olumlu sonuçlar konusunda firmaların bilgi eksikliği de ortaya çıkan bir diğer tespit olmuştur. Bu bağlamda şirketlerin elektronik ağ kültürünün dışsal görünümünü oluşturan WEB sayfalarında yer alan ifadelerin ısmarlama ve taklit suretiyle geliştirilen reklam objeleri olmaları yerine, başta vizyon ve misyon ifadeleri olmak üzere örgütsel kültürün temel yapı taşı ve yansımaları olan bildirgelerin elektronik ağ kültürüne yansıtılması konusundaki bilinç düzeyinin geliştirilmesinin sağlanması yukarıda belirtilen zorunluluklar kapsamında önem arz etmektedir. Özellikle gerek misyon-vizyon ifadelerinin gerekse insan kaynağı içeriğinin, anlaşılabilir, ayrıştıııcı özellikler yansıtması elzem hale gelmiştir.

İşletmeler açısından; elektronik ağ ve örgüt kültürü oluşumunun tek paydada birleştirilerek misyon ve vizyon ifadeleri yanında, bir takım seremoniler açısından da değerlendirilmesi ve yansıtılması gerekmektedir. İşletmeler; elektronik ağlarına örgüt kültürünü pekiştiren, aitlik, bağlılık, motivasyon ve/veya vatandaşlık kavramlarına hizmet eden özellikte; çalışanların isim ve görevleri, özel kutlama haber ve fotoğrafları, ayın çalışanı vb. bilgilere yer vermelidirler. İşletmelerin elektronik ağ kültürünü oluşturmaları ve yönetmeleri yalnızca dış müşteriye yönelik olarak hazırlandığı varsayılan misyon ve vizyon ifadelerinden daha fazla olguyu iç müşteri perspektifinden de yansıtma amacı taşımalıdır. Bugün gelinen noktada elektronik ağ temelli yeni bir kültürün oluştuğunu kabul etmek ve buna uygun strateji uygulamalarına yer vermek gerekliliği doğmuştur. Ayrıca elektronik ağ kültürü döneminde, web sitelerine iş görenlerin isimlerini, faaliyetlerini veya fotoğraflarını koymaları, mali açıdan bir yük gibi görünse de, esasında iş gören motivasyonunu sağlamak için harcanan para ve zamandan fazla olmayabilir. Çeşitli tatminsizlikler neticesinde nitelikli iş görenin işten ayrılmasının işletmelerde toplamda oluşturduğu maddi kayıp düşünülecek olursa, örgüt kültürünü yansıtan seremonilerin web üzerinden yansıtılması da, iş görenin ve tüm örgütün işletmeye bağılı̆̆ını ve verimliliğini artırabilecek, getirileri olan bir etken olarak karşımıza çıkmaktadır. 


\section{KAYNAKÇA}

Aktan, C. C. (2008), Stratejik Yönetim Ve Stratejik Planlama, Çimento-işveren Dergisi, Temmuz-Ağustos 4 (22): 4-21.

Baker, K. (2002), Chapter 11. Organizationalculture, 8 August, Http://Www.Au.Af.Mil/Au/Awc/Awcgate/Doe/Benchmark/Ch11.Pdf, Erişim Tarihi 25.08.2014: 1-13.

Belin, M. N.; Yıldız, H. (2011), Lise Öğrencilerinin Facebook Adlı Sosyal Paylaşım Sitesini Kullanma Amaçları Üzerine Sosyolojik Bir İnceleme: Eskişehir Örneği, Türkiye Bilimsel Ve Teknolojik Araştırma Kurumu, Sosyoloji Alanı Orta Öğretim Öğrencileri Arası Araştırma Projeleri Yarışması, Ocak, Bursa: 101.

Çamkara, A. (2007), Teknoloji Ve Kültürel Endüstri: “Web”ten “Cep”e Alkışların Dönüşümü, Millî Folklor, 19 (75): $27-29$.

Bart, C. (2007), A Comparative Analysis Of Mission Statement Content In Secularandfaithbasedhospitals, Journal Of Intellectualcapital, 8 (4): $682-694$

Doğan, H. (2008), Örgütlerde Vizyon Ve Misyonların Çalışanlarca Kabulü Ve Adnan Menderes Üniversitesi Örneği, Gazi Üniversitesi İktisadi Ve İdari Bilimler Fakültesi Dergisi, 10 (3): 93-110.

Erdem, R.; Adıgüzel, O.; Kaya, A. (2010), Akademik Personelin Kurumlarına İlişkin Algıladıkları Ve Tercih Ettikleri Örgüt Kültürü Tipleri, Erciyes Üniversitesi İktisadi Ve İdari Bilimler Fakültesi Dergisi, Sayı: 36, Ağustos-Aralık: 73-88.

Eren, E.; Alpkan, L.; Ergün, E. (2003), Kültürel Boyutlar Olarak İşletmelerde İçsel Bütünleşme Ve Dışsal Odaklanma Düzeylerinin Performansa Etkileri, Doğuş Üniversitesi Dergisi, 4 (1): 55-70.

Güçlü, N. (2003), Örgüt Kültürü, Kırgızistan Manas Üniversitesi, Sosyal Bilimler Dergisi, Sayı 6: 147-159.

Karakışla, E. (2009), Kültür-Yönetim İlişkileri Bağlamında Örgütsel Değişim Sürecine Örgütsel Kültürün Yönetsel Etkinlik Açısından Etkisi, Yüksek Lisans Tezi, Karamanoğlu Mehmetbey Üniversitesi Sosyal Bilimler Enstitüsü Kamu Yönetimi Ana Bilim Dalı, Karaman.

Kaya, H. (2008), Kamu Ve Özel Sektör Kuruluşlarının Örgütsel Kültürünün Analizi Ve Kurum Kültürünün Çalışanların Örgütsel Bağlılığına Etkisi: Görgül Bir Araştırma, Maliye Dergisi, Sayı 155, Temmuz-Aralık: 119-143.

Kılıç, M. (2010), Stratejik Yönetim Sürecinde Değerler, Misyon Ve Vizyon Kavramları Arasındaki İlişki, Sosyo-Ekonomi Dergisi, Sayı 2, Temmuz-Aralık: 81-98.

Kılıç, A.; Eren, H.; Gürsoy, A. (2014), Yenilikçilik Faktörlerinin Örgütlerin Vizyon Ve Misyon Ifadelerindeki Varlığı; Fortune Türkiye İlk 100 Firma Örneği, İşletme Araştırmaları Dergisi 6 (4): 36-68.

Köseoğlu, M. A. (2008), İşletmeler Var Olma Sebeplerini Nasıl ifade Ederler?: Kobi'lerin Misyon Ifadeleri Üzerine Bir Araştırma, Celal Bayar Üniversitesi i.i.B.F. Yönetim Ve Ekonomi Dergisi 15(2): 89-97.

Melewar, T.C. (2003), Determinants Of' Thecorporateidentityconstruct: A Rewiev Of The Literatüre", Journal Of Marketing Communications, Sayı: 9: 195-220, (Çev. Zeliha Hepkon, İstanbul Ticaret Üniversitesi Dergisi, File:///C:/Users/User/Desktop/\%C3\%B6rg\%C3\%Bctsel\%20k\%C3\%Bclt\%C3\%Bcr/Kurumsal\%20k\%C4\%B0ml\%C4\%B0k\%20\%C4\%B0n\%C5\%9ea sını\%20bel\%C4\%BOrleyen\%20fakt\%C3\%96rler.Pdf, Erişim Tarihi 30.01.2015).

O'donnell, O.; Boyle, R. (2008), Understandingandmanaging- Organisationalculture, Irelandınstitute Of Public Administration İn Association with the committeeforpublic Management Research, British Library Cataloguing İn Publication Data, Isbn: 978-1-904541-75-2, Issn: 13936190: 1-95

Özaydın, B. (2010), Teknoloji Kültürü Ve Etik, Yüksek Lisans Tezi, Süleyman Demirel Üniversitesi Fen Bilimleri Enstitüsü, Eğitim Teknolojileri Anabilim Dalı Isparta.

Tüik, (2015), Hanehalkı Bilişim Teknolojileri Kullanım Araştırması, TurkStat, Information and Communication Technology (ICT) Usage Survey in Households and Individuals, 2004-2015 (http://www.tuik.gov.tr/, erişim tarihi 01.05.2016).

Yalçın, İ.; Seçkin, Z.; Demirel, Y. (2009), Bilgideki Değişimin Örgütsel Değişime Etkisi Üzerine Bir İnceleme, Niğde Üniversitesi ïiBF Dergisi, Haziran, 2 (1): 48-69.

Yılmaz, Ş.; Aydın, F. (2013), Ortaokul Öğrencilerinin Teknolojiye Yönelik Tutumlarının Ve Tutumlarını Etkileyen Faktörlerin İncelenmesi”, Asya Öğretim Dergisi, $1(2): 1-17$. 